\title{
Dicionário As Mulheres e a Unidade Europeia
}

Dictionary Women and European Unity Instituto de História Contemporânea, Faculdade de Ciências Sociais e Humanas da Universidade Nova de Lisboa, Portugal ibaltazar@fcsh.unl.pt 
Na senda do Dicionário das Grandes Figuras Europeias (2919), surge agora o Dicionário das Mulheres e a Unidade Europeia, para suprir uma lacuna de quase ausência de mulheres no primeiro, mas perseguindo o mesmo objetivo de dar visibilidade aos grandes vultos que contribuíram para uma Europa Unida nos séculos XIX e XX, quer os grandes pensadores da Ideia de Europa, quer os estrategas e políticos que apresentaram projetos políticos para essa unidade europeia. Tendo como objetivo apresentar os grandes protagonistas da ideia de Europa, as suas reflexões sobre o passado, presente e futuro da Europa, e os políticos que empreenderam esforços concretos para realizar essa ideia e contribuírem para o processo de construção europeia.

Acabou de sair, a 29 de junho, este volume, o Dicionário das Mulheres e a Unidade Europeia, com os apoios da embaixadora Ana Paula Zacarias, Secretária de Estado dos Assuntos Europeus, e Rosa Monteiro, Secretária de Estado para a Cidadania e a Igualdade, bem como o Alto Patrocínio do Presidente da República, ambos sob a chancela das edições Parlamento.

Este novo Dicionário das Mulheres e a Unidade da Europa pretendeu dar visibilidade às mulheres portuguesas e europeias que se envolveram a pensar a Europa e a construção de uma unidade europeia durante os séculos XIX e XX. Em Portugal, são de destacar as figuras de Irene de Vasconcelos, Elina Guimarães e Maria de Lourdes Pintasilgo. A primeira participou na discussão sobre o Projeto Federal Europeu de Aristides Briand, no seio da Sociedade das Nações. A segunda, na mesma época, mas em Portugal, revelou conhecer bem a discussão sobre 0 projeto europeu, através da página feminista da Revista Portugal Feminino. Maria de Lourdes
Pintasilgo, a mulher com projeção nacional e internacional, conciliou o pragmatismo político com a reflexão sobre a Europa, ficando na história de 30 anos de integração de Portugal na Europa. Mas também, Helena Vaz da Silva, Natália Correia, Maria Lamas e Judith Teixeira, tiveram um papel fundamental numa Europa da Cultura.

A nível europeu, refira-se a figura de Louise Weiss, a europeísta convicta que, ao lado de Aristides Briand, defendeu a unidade europeia de forma tão convicta e assumida que, justamente, ficou para a história como a "Avó Europa". E as reflexões de Maria Antonietta Macchiocchi sobre a Europa, que são a afirmação da necessidade vital de uma Europa da Cultura para o futuro do projeto europeu. Mas também outros nomes de projeção como Ursula Hirschmann, Sophie Scholl, Simone Veil, Nicole Fontaine e Angela Merkel, e tantas outras menos conhecidas, mas com trabalho reconhecido em prol da unidade europeia.

$\mathrm{Na}$ realidade, as mulheres tiveram um papel importante em pensar a Ideia de Europa e a unidade europeia, assim como também têm sido intervenientes - algumas delas com muito destaque - no processo de construção europeu. Mesmo assim, muitas delas permaneceram, quase, na total invisibilidade e só eram reveladas, no caso de Louise Weiss, porque aparecia ao lado de Aristide Briand, o conhecido estadista, portanto ao lado de protagonistas da História, ou assinando páginas da imprensa, que nos davam conta da sua existência, mas que, muitas delas, ainda permanecem por revelar ao conhecimento público e a um público mais heterogéneo.

Todas as obras têm um objetivo e esta resultou de uma motivação de que As Mulheres e a Unidade Europeia podia acrescentar algo de novo à comunidade científica, ou ser um contributo para leitores de um público mais 
alargado, para conhecerem as principais figuras femininas europeias, que lhes abrirão, certamente, novas perspetivas sobre 0 essencial do projeto europeu. As coordenadoras, no prosseguimento da sua investigação em história da integração europeia tiveram como pergunta: onde estavam as Mulheres durante 0 processo de unificação europeia? - questão que constituiu o nosso ponto de partida de uma nova investigação.

A Europa tem "Pais da Europa" e "Mães da Europa": então porque conhecemos tão bem os primeiros e quase desapareceram as segundas, ou, porque não tiveram visibilidade? A verdade é que a Europa foi feita de projetos que envolveram homens e mulheres e torna-se necessário reabilitar a sua memória. Foi esse trabalho de Hércules que percorremos nesta obra, primeiro para identificar essas figuras femininas, depois para as conhecer, porque muitas delas permaneciam totalmente desconhecidas. Foi este o problema identificado e ponto de partida para a investigação.

As Mulheres e a Unidade Europeia, propôs-se colaborar com o levantamento da Memória das Mulheres que contribuíram para a Construção Europeia, quer pelas ideias apresentadas, quer pela ação prática e intervenção nas instituições europeias. Estas mulheres tiveram um papel muito importante logo a seguir à I Guerra Mundial, apresentando propostas concretas para salvaguardar a paz através da União da Europa, e o seu envolvimento permanece de 1957 a 2020.

Estas memórias femininas têm como principal objetivo dar visibilidade à participação feminina, muito particularmente, desde a primeira guerra e a partir de 1950, na reflexão sobre a Europa e o seu futuro. Nesta investigação será mostrado que as mulheres, para além de um olhar sobre a situação europeia do seu tempo, apresentaram, ainda, a sua posição sobre os acontecimentos, quer na esfera privada quer na espera pública. 0 seu protagonismo revelar-se- ia surpreendente pela participação em organizações internacionais participando plenamente no processo da construção europeia.

A comum afirmação de que a Europa tem apenas "pais" fundadores, ficou determinada pelo quadro retratado quando os políticos europeus se uniram na construção da comunidade nos anos 1950. Nessa altura, nenhuma mulher aparece nas fotos deste marco decisivo da construção europeia, revelando aparentemente que elas têm pouca relevância na vida política nacional dos seis Estados construtores, ainda que possamos identificar algumas delas, à sombra dos fundadores, e que foram muito importantes para o projeto europeu, embora não sejam tão conhecidas e faladas como os homens. Mas estiveram sempre nos bastidores dessa invisibilidade, inspirando e participando na construção do projeto europeu. Esta ausência inicial de mulheres parecia sugerir que não intervieram na construção da Europa. Mas 0 que é verdade é que sempre estiveram presentes, quer nas décadas de 1950 e 1960, e com muito maior visibilidade a partir dos anos 1980.

Foram as Mulheres a empreenderem a concretização dos Valores da Europa, o primeiro de todos, o objetivo essencial da Paz, sem o qual não seria possível qualquer unidade europeia e, ainda menos, colocar as primeiras pedras do edifício europeu, nesse processo de construção europeia pós-segunda guerra, que se seguiu ao sentimento da necessidade de unidade europeia, pós I Guerra. Tanto num momento como no outro, embora fossem os políticos a criarem formalmente essa Europa dos primeiros passos, como a designava Robert Schuman, as mulheres muito contribuíram para o pacifismo, condição essencial para qualquer tratado político.

De facto, as Mulheres são as grandes pacifistas. A Europa terá de recuperar o seu passado e desejar manter as suas raízes 
enquanto civilização. Por isso, há que evitar a constituição de impérios que absorvam as pequenas nações, sem as quais essa Europa perderá a sua identidade. 0 espírito europeu não pode ser mutilado. Para isso, precisa de afastar uma política de dominação e conservar os pequenos estados, todos unidos para conservar a grandeza europeia. Todas as grandes nações devem trabalhar efetiva $e$ eficazmente pela Paz, como teorizava Andrade Corvo, na obra Perigos. As Mulheres assumiram estes perigos como uma ameaça à paz, a evitar a todo o custo, estando presentes na Liga para a Paz e em todos os Congressos para a Paz. Foi neste papel fundamental que fomos encontrar muitas das biografadas nesta obra. Convictamente trabalhavam pela Paz e por dar à Europa uma política fundamentada no direito e na justiça, que assegurasse a tranquilidade, a prosperidade e a liberdade dos povos. Nenhum Estado europeu poderia ficar indiferente à guerra dos outros, todos perdendo com os perigos que ameaçam a civilização da liberdade e do direito.

As Mulheres vieram mostrar a possibilidade de uma "Europa Nova", nos efeitos de uma "Escola da Paz", nos Direitos da Mulher e num feminismo representado pela "Nova Mulher". Vieram mostrar com grande convicção de que a unidade da Europa e dos europeus era uma necessidade. Todas elas, de uma forma ou de outra, acreditaram nesta Europa, fundada nas suas experiências de vida muito ricas, também extraeuropeias, portanto, a partir do contacto direto com a vida e não uma ideia ensaiada teoricamente. Conhecem outras civilizações, outros povos, outras culturas. Naturalmente, esta diversidade geográfica, cultural e religiosa, muito contribuíram para a formação de um espírito aberto à unidade na diversidade, princípio fundamental da cultura europeia. Desde cedo, as Mulheres conviveram com esta realidade, o que lhes permitiu terem uma visão aberta da unidade europeia e, mesmo, de uma unidade da humanidade. Afinal, não serão estas
Mulheres sem fronteiras, como foram outras figuras lapidares da Europa, como Coudenhove-Kalergi, Jean Monnet, Robert Schuman e Adenauer? Mulheres que acreditam verdadeiramente numa unidade europeia, também com contornos geográficos, que eliminam todas as fronteiras artificiais traçadas entre os povos?

Curiosamente podemos constatar como as grandes impulsionadoras da União Europeia não se tornaram europeias por nascimento, ou seja, por herança, mas essa herança que constitui a sua história familiar, muito contribuiu para serem abertas à diversidade e universalidade. 0 seu espírito cosmopolita foi impulsionado pela sua própria vivência, foram mulheres visionárias da necessidade de uma Europa Unida, percebendo que esta unidade não se pode fundamentar-se em interesses económicos, mas, em valores lapidares que fazem parte de uma consciência europeia.

Para nós, os leitores, a grande lição é ficar com a consciência de que todas as teorias precisam de uma sustentabilidade social e política. Não ter a ilusão da possibilidade de inventar um futuro para a Europa, sem ter consciência dessa realidade europeia. Não desligar 0 pensamento da prática vivida. Enfim, não criar uma torre de marfim!

Muitas destas mulheres, como, por exemplo, Irene de Vasconcelos conseguiram a proeza de presenciar os principais acontecimentos no mundo e, particularmente, na Europa. Escreviam na imprensa, no caso citado, no Diário de Lisboa, em Paris, da Nation (Madrid) e de El Mundo (Havana). Colaborou ainda, de forma esporádica, no Diário de Notícias, em La Nation (Buenos Aires), L'Independence Roumaine, Ahora e Excelsior (México). Participavam na política internacional, muito concretamente, na Sociedade das Nações. As suas Ideias de Europa foram arquitetadas a partir de uma realidade vivida.

Estas Mulheres Europeias denotavam um grande interesse pelo mundo em que viviam, 
um envolvimento nas grandes causas que se discutiam na época, ultrapassando muito os acontecimentos internacionais que enchiam as primeiras páginas dos jornais, captando, também, as lutas difíceis e menos visíveis, nomeadamente no domínio da afirmação dos Direitos da Mulher, que naquela época pretendiam triunfar. Muitas acreditavam mesmo na possibilidade dos "Estados Unidos da Europa".

Foi um projeto, sem dúvida arrojado, devido à grande invisibilidade destas mulheres na sociedade e, por isso, à escassez das fontes disponíveis que, segundo as coordenadoras, as obrigou a caminhar, como a própria Europa, pelo "método dos pequenos passos". No entanto, foi um desafio que se revelou fascinante pelas contínuas descobertas que a viagem pela Europa foi proporcionando, muitas vezes com encruzilhadas, que conduziram a novos caminhos e à revelação de outras mulheres que foram acrescentando à investigação. Neste labirinto o fio condutor foi sempre, dar visibilidade às mulheres que pensaram a Europa, sendo ou não protagonistas da sua história, através das suas vidas.

Este livro pretende ser uma obra de referência nesta temática e servir de manual didático para alunos do ensino superior, bem como ponto de partida para investigações aprofundadas em monografias ou teses. Nele colaboraram 79 autores para 79 Figuras, sendo de destacar textos de Leonor Machado de Sousa, Anne Cova, Adriano Moreira, Guilherme d' Oliveira Martins, Manuel Lopes Porto, entre tantos outros prestigiados académicos.

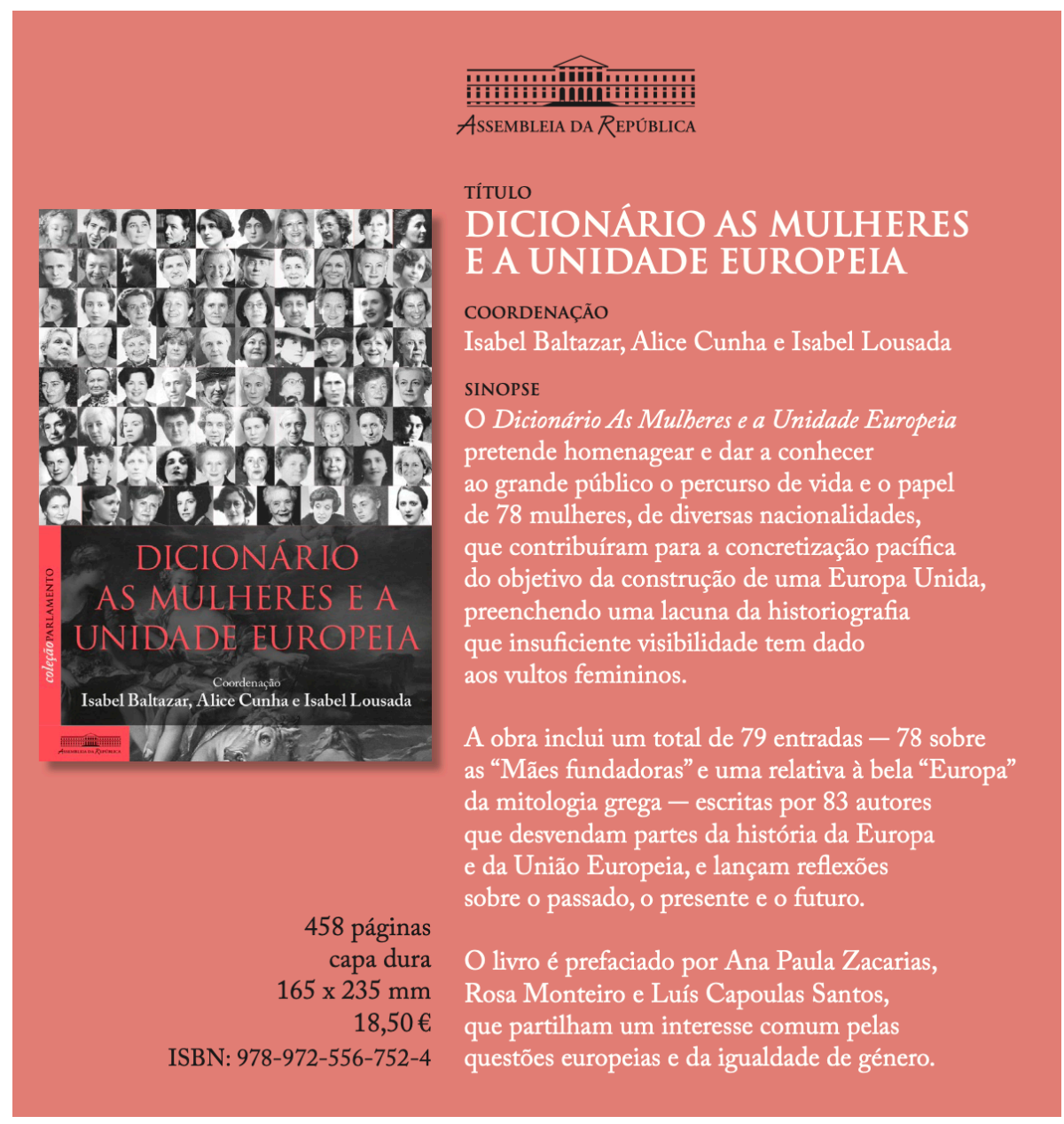

